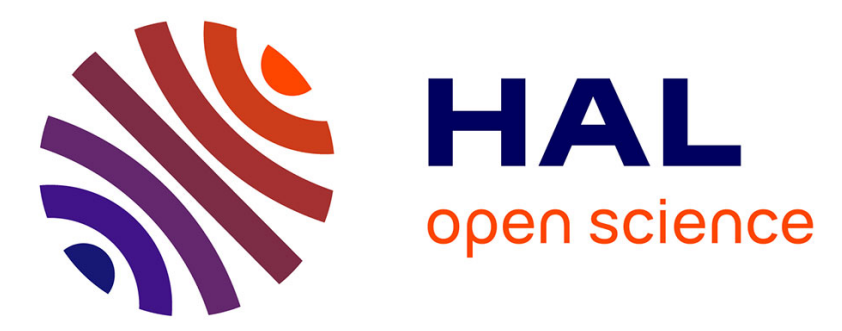

\title{
Characterization of CrN/CrAlN/Cr2O3 Multilayers Coatings Synthesized by DC Reactive Magnetron Sputtering
}

Khalil Aouadi, Brahim Tlili, Corinne Nouveau, Aurélien Besnard, Moez Chafra

\section{To cite this version:}

Khalil Aouadi, Brahim Tlili, Corinne Nouveau, Aurélien Besnard, Moez Chafra. Characterization of CrN/CrAlN/Cr2O3 Multilayers Coatings Synthesized by DC Reactive Magnetron Sputtering. CMSM: International Conference Design and Modeling of Mechanical Systems, Mar 2019, HAMMAMET, Tunisia. pp.586-594, 10.1007/978-3-030-27146-6_63 . hal-02505338

\section{HAL Id: hal-02505338 https://hal.science/hal-02505338}

Submitted on 11 Mar 2020

HAL is a multi-disciplinary open access archive for the deposit and dissemination of scientific research documents, whether they are published or not. The documents may come from teaching and research institutions in France or abroad, or from public or private research centers.
L'archive ouverte pluridisciplinaire HAL, est destinée au dépôt et à la diffusion de documents scientifiques de niveau recherche, publiés ou non, émanant des établissements d'enseignement et de recherche français ou étrangers, des laboratoires publics ou privés. 


\title{
Characterization of $\mathrm{CrN} / \mathrm{CrAlN} / \mathrm{Cr}_{2} \mathrm{O}_{3}$ Multilayers Coatings Synthesized by DC Reactive Magnetron Sputtering
}

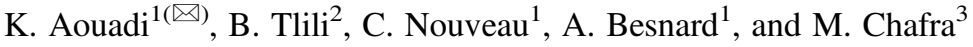 \\ ${ }^{1}$ LaBoMaP, Arts et Métiers ParisTech, Rue Porte de Paris, Cluny 71250, France \\ aouadikhalil@hotmail.com, \\ \{corinne. NOUVEAU, aurelien.BESNARD\}@ensam. eu \\ ${ }^{2}$ Université de Tunis, El-Manar Ecole Nationale d'Ingénieurs de Tunis, \\ LR-11-ES19, Laboratoire de Mécanique Appliquée et Ingénierie (LR-MAI), \\ 1002 Tunis, Tunisia \\ tliliibrahim@yahoo.fr \\ ${ }^{3}$ Laboratoire de Systèmes et de Mécanique Appliquée, \\ 2078 La Marsa, Tunis, Tunisie \\ chafra_moez@yahoo.fr
}

\begin{abstract}
The $\mathrm{CrN} / \mathrm{CrAlN} / \mathrm{Cr}_{2} \mathrm{O}_{3}$ multilayer coatings were deposited by reactive magnetron sputtering $\mathrm{DC}$ on $90 \mathrm{CrMoV} 8$ stainless steel under various oxygen flow rates. The structure and crystalline phases are characterized by the x-ray diffractometer. Through SEM, a dense and coherent is revealed in $\mathrm{CrN} / \mathrm{CrAlN} / \mathrm{Cr}_{2} \mathrm{O}_{3}$ multilayer coatings. The friction and wear behaviors obtained with the ball-on-disc test show that all multilayer films exhibit a good wear resistance, especially the one with an oxygen flow rate of $10 \mathrm{sccm}$. Nevertheless, in sea water the film without a top layer of $\mathrm{Cr}_{2} \mathrm{O}_{3}$ have the lowest coefficient of friction. This behavior is attributed to the interfacial strengthening and the existence of the upper passivation layer $\mathrm{Cr}_{2} \mathrm{O}_{3}$. Adding to that, the film obtained under an oxygen flow rate of $10 \mathrm{sccm}$ show the lowest grain size and the maximum hardness and elastic modulus could respectively, 45 and $417 \mathrm{GPa}$.
\end{abstract}

Keywords: Multilayer coatings $\cdot$ Microstructure $\cdot$ Hardness $\cdot$ Wear

\section{Introduction}

Oxide thin films coatings are widely used in different applications. They are known by their good oxidation resistance, good corrosion resistance, good wear resistance and good thermal properties [1, 6, 13]. However, when applied as individual coatings, oxides films haven't good properties.

To enhance the hardness of by developing super-lattice [8], some researchers studied an oxide/oxide structure. Nevertheless, in some cases, hardness has not been improved specially for $\mathrm{Al}_{2} \mathrm{O}_{3} / \mathrm{ZrO}_{2}$ super-lattice [23]. This is explained either by the fact that the shear modulus of the two oxides is similar, or by the formation of an amorphous phase. In fact, Chang et al. [6] deposited an electrolytic $\mathrm{ZrO}_{2} / \mathrm{Al}_{2} \mathrm{O}_{3}$ double layer coating by varying temperature. They note that the maximum hardness is about 
7.2 GP under a temperature of $300{ }^{\circ} \mathrm{C}$. Likewise, they observed that $\mathrm{ZrO}_{2} / \mathrm{Al}_{2} \mathrm{O}_{3}$ multilayer coating has a very good corrosion behavior with a corrosion resistance which is 10 times higher than that of uncoated steel. Recently nitride/oxide super-lattice with high hardness has been successfully developed. Studies have shown that these thin films have a good hardness which can reach $45 \mathrm{GPa}$. However, these super-lattices have relatively low deposition times. Many researchers have been made to increase the deposition time of these super-lattices using reactive magnetron sputtering technique. Yue et al. [25] developed $\mathrm{VN} / \mathrm{SiO}_{2}$ multilayers with $\mathrm{SiO}_{2}$ thicknesses ranging from 0.45 to $1.70 \mathrm{~nm}$. They showed that when the thickness of $\mathrm{SiO}_{2}$ is less than $1 \mathrm{~nm}$, multilayer films crystallized according to the $\mathrm{VN}$ matrix and the two layers exhibit epitaxial growth. The hardness of this coating increases to $34 \mathrm{GPa}$. Li et al. [15] developed $\mathrm{TiAlN} / \mathrm{SiO}_{2}$ films by reactive magnetron sputtering. They found that hardness reaches his maximum $\left(37 \mathrm{GPa}\right.$ ) when the thickness of $\mathrm{SiO}_{2}$ is about $0.6 \mathrm{~nm}$. However, the variation of the thickness of the VN layer has no effect on the mechanical and structural properties.

Chromium oxide, $\mathrm{Cr}_{2} \mathrm{O}_{3}$, is an oxide which has been used as a protective coating of cutting tools due to its outstanding wear and corrosion resistance. It's known by its high hardness and melting temperature, good resistance to wear and high oxidation temperature [5]. In order to improve the properties of chromium oxides, several researchers have studied the effect of increasing the oxygen content. Luo et al. [19] developed chromium oxides by RF magnetron sputtering by varying oxygen flow. They showed that as oxygen flow increases from 2.3 to $3.22 \mathrm{sccm}$, the hardness increases rapidly from 8 to $30 \mathrm{GPa}$. Hones et al. [10] deposited $\mathrm{Cr}_{2} \mathrm{O}_{3}$ films by $\mathrm{RF}$ magnetron sputtering. They showed that the grain size of chromium oxides increases linearly with the deposition temperature. However, with the increase of the oxygen level, the grain size increases initially and then remains constant for a percentage of $20 \%$ at. Similarly, they showed that the hardness significantly depends on the $\mathrm{O}_{2}$ content since it reaches a maximum value of $31 \mathrm{GPa}$ for an oxygen content between 15 and 25 at.\%. Nevertheless, for an $\mathrm{O}_{2}$ content of $30 \%$ at. The hardness is very low $(2.5$ GPa). Liu et al. [17] developed $\mathrm{Cr}_{2} \mathrm{O}_{3}$ films by plasma glow discharge with different oxygen flow rates $(5,10,15$ and $20 \mathrm{sccm})$ over a chromium nitride film as a top layer. They studied the corrosion resistance in an aqueous $3.5 \% \mathrm{NaCl}$ solution. They observed that the application of a thin layer of $\mathrm{Cr}_{2} \mathrm{O}_{3}$ on the stainless steel greatly improves its corrosion resistance. Ho et al. [9] deposited $\mathrm{Cr}_{2} \mathrm{O}_{3}$ films on a $\mathrm{CrN}$ layer as a top layer. The adhesion test shows the appearance of cracks which is probably due to the improved hardness of $\mathrm{Cr}_{2} \mathrm{O}_{3}$. The addition of a top layer of $\mathrm{Cr}_{2} \mathrm{O}_{3}$ also lowered the coefficient of friction.

In this work we present results multilayers films $\mathrm{CrN} / \mathrm{CrAlN} / \mathrm{Cr}_{2} \mathrm{O}_{3}$ were synthesized through using DC magnetron sputtering technique. The effect of oxygen rate on the properties of the top layer $\mathrm{Cr}_{2} \mathrm{O}_{3}$ is studied. In this study, the chemical composition, microstructure, mechanical, and tribological properties of the multilayer coatings $\mathrm{CrN} / \mathrm{CrAlN} / \mathrm{Cr}_{2} \mathrm{O}_{3}$ coatings were investigated. 


\section{Experimental Procedures}

The $\mathrm{CrN} / \mathrm{CrAlN} / \mathrm{Cr}_{2} \mathrm{O}_{3}$ multilayer coatings were deposited by DC reactive magnetron sputtering (KENOSISTEC-KS40V).

Before deposition, substrates were in situ etched under argon plasma at $-700 \mathrm{~V}$ for 10 min to ensure a better adhesion of the coatings. The base pressure prior to sputtering was lower than $2.10^{-5} \mathrm{~Pa}$ and heated at $300{ }^{\circ} \mathrm{C}$. During deposition, the working pressure was $0.5 \mathrm{~Pa}$.

For the deposition process, chromium and aluminum target with purity of $99.95 \%$ was used. To deposited $\mathrm{CrN}$ and $\mathrm{CrAlN}$ monolayers The $\mathrm{Cr}$ and $\mathrm{Al}$ target power was set respectively at $1500 \mathrm{~W}$ and $1000 \mathrm{~W}$ and flow rates of $\mathrm{Ar}$ and $\mathrm{N}_{2}$ were 68.8 and 33.3 sccm, respectively. For the $\mathrm{Cr}_{2} \mathrm{O}_{3}$ thin films, the $\mathrm{Cr}$ target power was set at $1500 \mathrm{~W}$. The flow rate of $\mathrm{O}$ was determined with the hysteresis experimental. After this experimental process, the flow rate of oxygen chosen is 0,10 and $20 \mathrm{sccm}$. A substrate bias voltage of $-500 \mathrm{~V}$ is applied to all coatings during deposition. Before deposited $\mathrm{CrN} / \mathrm{CrAlN} / \mathrm{Cr}_{2} \mathrm{O}_{3}$ multilayer film, a thin layer about $120 \mathrm{~nm}$ Of $\mathrm{Cr}$ is deposited to ensure the adhesion of the coating.

The microstructure and surface morphology of the multilayer coatings were observed by SEM field emission (JEOL JSM 7610F). The friction coefficient is determined by rotative ball-on-disk tests. The applied fixed load was $5 \mathrm{~N}$ and the sliding speed was $3 \mathrm{~cm} / \mathrm{s}$. The counterpart used is an alumina ball $\left(\mathrm{Al}_{2} \mathrm{O} 3\right) 6 \mathrm{~mm}$ of diameter. The distance slide by the ball is about $200 \mathrm{~m}$. The wear volume of different coatings was calculated from 3D optical profilometer (VEECO, Wyko NT-1100) profiles. The wear volume was calculated from profilometer profiles. To be more precise, eight sections of depth in the wear track are chosen. The film surfaces topography was analyzed by atomic force microscope (AFM) (type XE Park 70) using the tapping mode. An area of $25 \mu \mathrm{m}^{2}(5 \times 5)$ was scanned. Additional analyses with the Gwyddion software were performed to determine the RMS roughness of the multilayer coatings. The coating hardness was determined by nanoindentation tests using a MTS XP Nano indenter equipped with a Vickers indenter and using the Rahmoun's model [22]. The adhesion tests were carried out by means of a microscratch tester (Scratch Tester Millennium 200) equipped with Rockwell spherical diamond indenter. To calculate an average adhesion value, each test is repeated three times. Figure 1 illustrates a descriptive scheme of multilayer film.

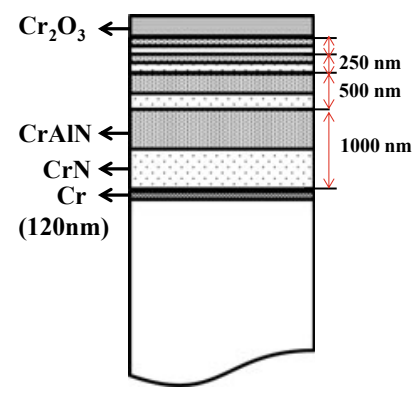

Fig. 1 Scheme of the multilayer systems 


\section{Results and Discussion}

\subsection{Microstructure and Morphology}

The observation of the SEM images of the cross-section and surface morphology of the multilayer coatings $\mathrm{CrN} / \mathrm{CrAlN} / \mathrm{Cr}_{2} \mathrm{O}_{3}$ was carried out using a high-resolution FEG SEM. Figure 2 shows the cross-section of the multilayer films without and with a top layer of $\mathrm{Cr}_{2} \mathrm{O}_{3}$.

(a)

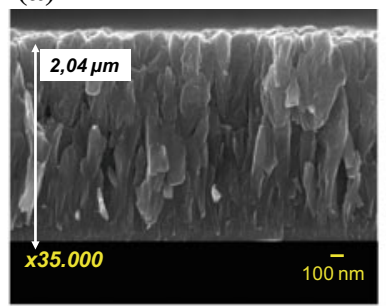

(a')

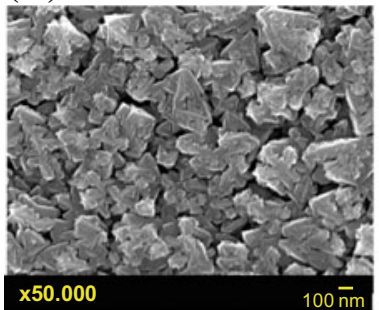

(b)

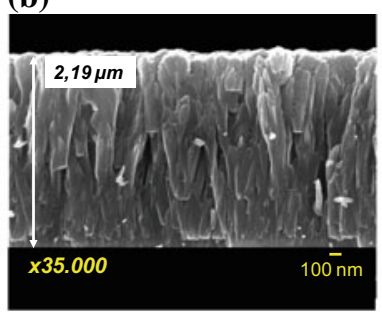

(b’)

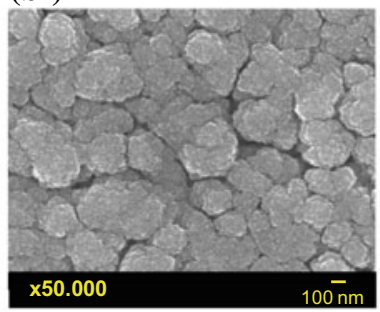

(c)

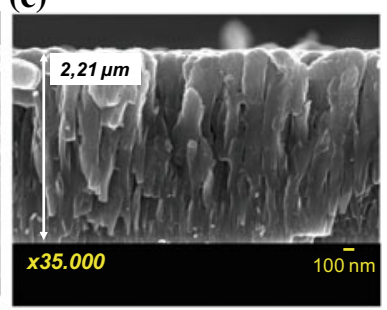

(c')

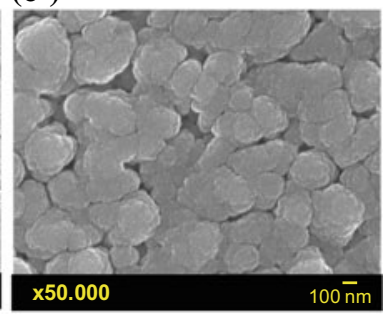

Fig. 2 Cross-sectional SEM image and surface morphology of multilayer films with a top layer of $\mathrm{Cr}_{2} \mathrm{O}_{3}$ at oxygen rate: (a, a') $0 \mathrm{sccm}\left(\mathbf{b}, \mathbf{b}^{\prime}\right) 10 \mathrm{sccm}\left(\mathbf{c}, \mathbf{c}^{\prime}\right) 20 \mathrm{sccm}$

All coatings represent a columnar and dense structure. The observations of the images of the surface morphology of the different multilayer coatings (Fig. 1a'-c') show that the application of a top layer of oxide leads to a variation of the shape of the columns. The film without a top layer of oxide present pyramid-like surface features. The presence of nano-pores between the columns is very visible. According to the Mahieu's model structure zones [20], this structure corresponds to the $\mathrm{I}_{\mathrm{c}}$ zone. By adding an oxide layer with a small amount of $\mathrm{O}_{2}(10 \mathrm{sccm})$, a rounded and assembled columnar tops appear and form a cauliflower-like structure. Always, according to the Mahieu's model, this structure corresponds to the zone II. This area is denser and more homogeneous than Ic area. We notice that the number of nano-pores decreases compared to the multilayer coating without top layer. By increasing the oxygen flow rate to $20 \mathrm{sccm}$, the surface is always smooth with very small columns which seem less granular than those obtained with an oxygen flow rate of $10 \mathrm{sccm}$.

The atomic force microscopy (AFM) images surface of multilayer films are presented in Fig. 2. 
(a)

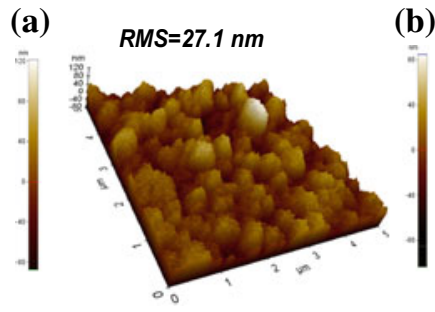

(b)

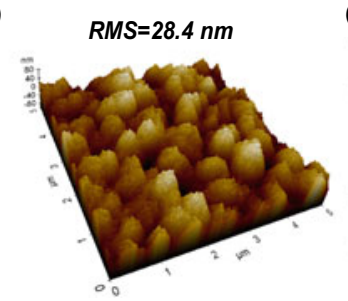

(c)

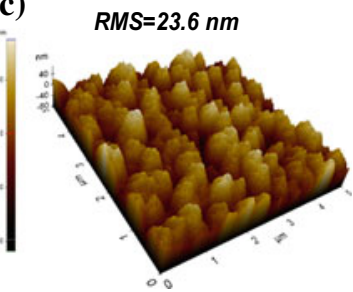

Fig. 3 Three-dimensional AFM of multilayer films with a top layer of $\mathrm{Cr}_{2} \mathrm{O}_{3}$ deposited on silicon substrate at oxygen rate: a $0 \mathrm{sccm}$ b $10 \mathrm{sccm}$ c $20 \mathrm{sccm}$

AFM images show that all multilayer films are homogeneous, dense and weakly porous. The morphology of these coatings appears to be a set of continuous mounds.

The roughness of coatings is also shown in Fig. 3. The films with a top layer of $\mathrm{Cr}_{2} \mathrm{O}_{3}$ obtained with an oxygen flow rate of $20 \mathrm{sccm}$, has the lowest roughness (23.6 nm). Generally, the growth of $\mathrm{Cr}_{2} \mathrm{O}_{3}$ films is determined by the diffusion current of $\mathrm{Cr}^{3+}$ ions and the oxygen rate adsorption. Also, with the increase in oxygen flow rate, the $\mathrm{O}_{2}$ adsorption rate can moderate the $\mathrm{Cr}$ diffusion current and leads to the formation of a denser $\mathrm{Cr}_{2} \mathrm{O}_{3}$ layer and more smooth [17].

\subsection{Mechanical Properties}

The hardness and Young modulus of the multilayers films as a function of the oxygen flow rate are shown in Fig. 4.

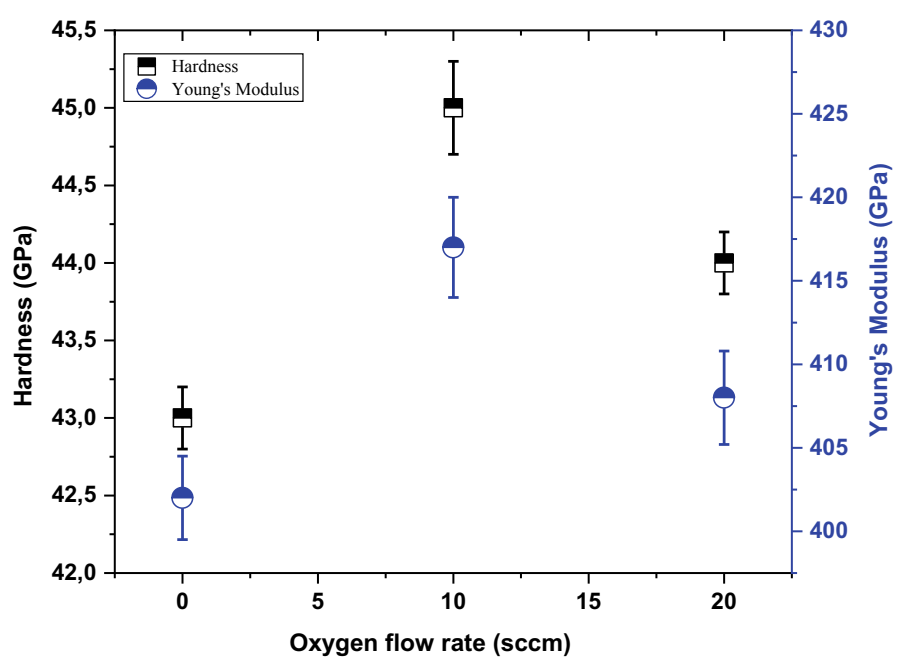

Fig. 4 Hardness and Young's modulus of multilayer films CrN/CrAlN/Cr ${ }_{2} \mathrm{O}_{3}$ 
Figure 4 show that the addition of a top layer of $\mathrm{Cr}_{2} \mathrm{O}_{3}$ obtained with $10 \mathrm{sccm}$ of oxygen flow rate causes an increase in hardness and Young's modulus and it reaches values of 45 and $417 \mathrm{GPa}$. However, for the coatings without top layer the hardness is about $43 \mathrm{GPa}$ and the Young's modulus is $402 \mathrm{GPa}$. This improvement can be attributed to the increase in the number of interfaces between the film of $\mathrm{Cr}_{2} \mathrm{O}_{3}$ and the $\mathrm{CrN} / \mathrm{CrAlN}$ coating. Indeed, the interfaces are considered as barriers to dislocation which prohibit the growth of columnar grains through the layers. Blocking dislocations due to column-to-column discontinuity contributes to improved hardness [21]. Also, increasing hardness may be attributed to the existing of hard oxide coating as a barrier to plastic deformation [2]. Likewise, good hardness of the coatings with top layer is due to the morphology of these films. In fact, the multilayer coating without top layer presents pores, however these pores disappear in films with $\mathrm{Cr}_{2} \mathrm{O}_{3}$ top layer (Fig. 2) [7]. Indeed, pores are known by their detrimental effect on hardness. Also, the strain effect and hall-Petch strengthening can explain the increasing of the hardness [14]. By increasing the oxygen flow rate to $20 \mathrm{sccm}$, hardness decrease to $44 \mathrm{GPa}$. Similar results have been shown by Barshilia et al. [3]. This decrease can be attributed to the decrease in hardness of the $\mathrm{Cr}_{2} \mathrm{O}_{3}$ layer. In fact, Luo et al. [18] developed $\mathrm{Cr}_{2} \mathrm{O}_{3}$ films by magnetron sputtering. They varied the flow of oxygen from 2 to $2.3 \mathrm{sccm}$ and showed that the hardness of chromium oxide decreases with this increase of the oxygen rate from 14 to $7 \mathrm{GPa}$. Barshilia et al. [4] attribute the decreasing of hardness to the voids appears during the growing films which influence the mechanical properties.

Figure 5 shows the $\mathrm{Lc}_{1}$ and $\mathrm{Lc}_{2}$ critical loads of the $\mathrm{CrN} / \mathrm{CrAlN} / \mathrm{Cr}_{2} \mathrm{O}_{3}$ multilayers films as a function of the oxygen flow rate.

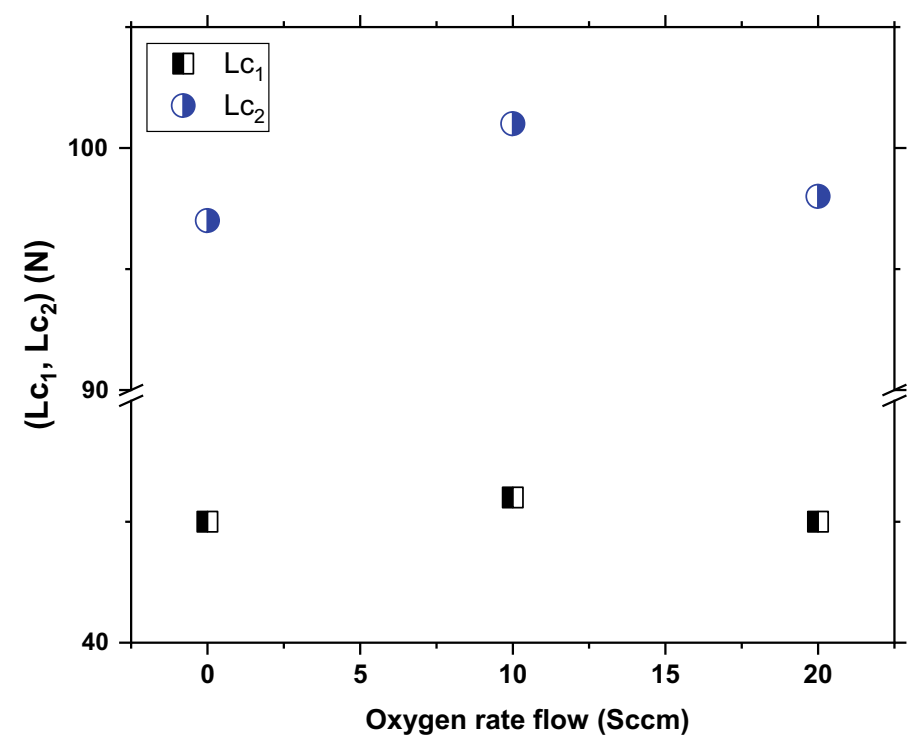

Fig. 5 Critical load of $\mathrm{CrN} / \mathrm{CrAlN} / \mathrm{Cr}_{2} \mathrm{O}_{3}$ multilayer coatings 
From Fig. 5 we have noticed that the addition of a top layer of oxide $\left(\mathrm{Cr}_{2} \mathrm{O}_{3}\right)$ to the CrN/CrAlN multilayers hasn't any effect on the force corresponds to the development of cracks $\left(\mathrm{Lc}_{1}\right)$. For $\mathrm{Lc}_{2}$, it increases when a layer of $\mathrm{Cr}_{2} \mathrm{O}_{3}$ is deposited as a top layer on the multilayer film and reaches a value of $102 \mathrm{~N}$, which is a more than respectable result for layers that should be used in mechanical applications. This improvement in adhesion is attributed to the increase in the number of interfaces [11]. Indeed, the interfaces can delay the propagation of cracks. In addition, the deposition of a small thickness of a layer $\mathrm{Cr}_{2} \mathrm{O}_{3}$ can form a coherent interface with CrAlN films resulting in a significant increase of adhesion. This improvement can also be due to the improvement of the microstructure. Indeed, when comparing Fig. 2a' with Fig. 2b', c', it can be shown that there exist less pores. For the $\mathrm{CrN} / \mathrm{CrAlN} / \mathrm{Cr}_{2} \mathrm{O}_{3}$ multilayer film obtained with a flow rate of oxygen of $20 \mathrm{sccm} \mathrm{Lc} 2$ slightly decrease. This may be due to the decrease of hardness (Fig. 4). Indeed, many researchers have reported that the critical load increases linearly with the hardness of coatings $[12,24]$ and this confirm our results.

\subsection{Coefficient of Friction}

Figure 6 shows the coefficient of friction (COF) of the $\mathrm{CrN}$ films after sliding against $\mathrm{Al}_{2} \mathrm{O}_{3}$ balls (normal load of $5 \mathrm{~N}$ ) as a function of oxygen flow rate.

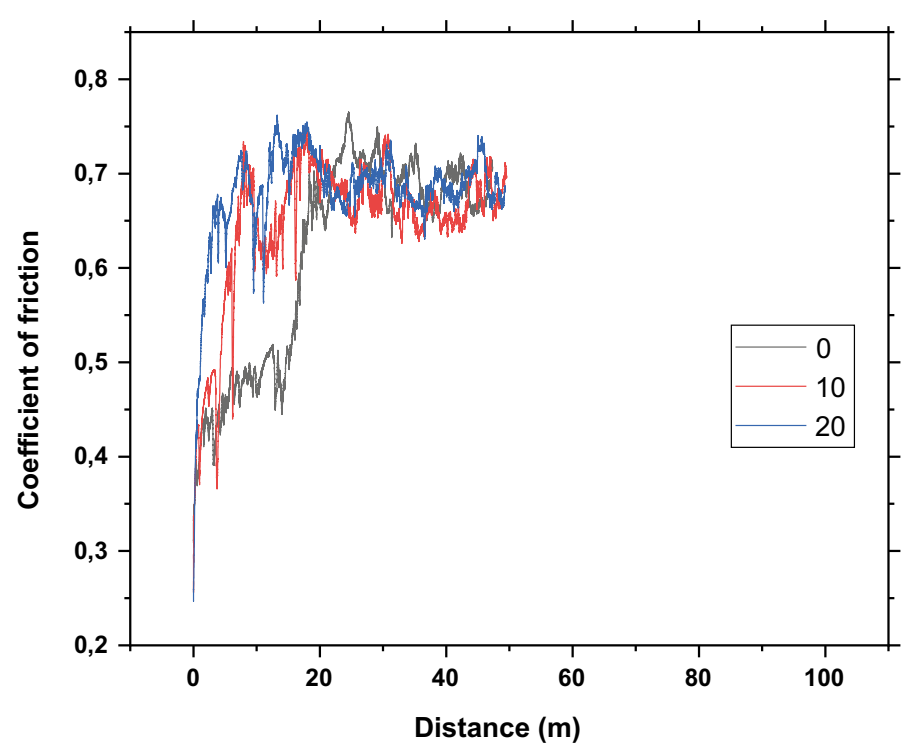

Fig. 6 Coefficient of friction of $\mathrm{CrN} / \mathrm{CrAlN} / \mathrm{Cr}_{2} \mathrm{O}_{3}$ multilayer coatings

From Fig. 6 we note that the addition of a layer of $\mathrm{Cr}_{2} \mathrm{O}_{3}$ hasn't any influence on the friction behavior. The coefficient of friction of the various multilayers is about 0.69. Ho et al. [9] have shown that the deposition of a $\mathrm{Cr}_{2} \mathrm{O}_{3}$ layer on a $\mathrm{CrN}$ layer has reduced its coefficient of friction from 0.4 to 0.26 . This is not the case for our films. 
This may be due to the thinness of our oxide top layer. In addition, the friction of the ball on the surface of the film can increase the amount of oxide due to the local increase in temperature. This new oxide can weaken the bond strength between the top layer of $\mathrm{Cr}_{2} \mathrm{O}_{3}$ and the layers below. In fact, if the oxygen atoms $(\mathrm{O})$ are sufficiently incorporated in the upper layer, it becomes more fragile and has cracks for a critical quantity of oxygen [16].

\section{Conclusion}

The main objective of the present work was to investigate the effect of a top layer of chromium oxide $\left(\mathrm{Cr}_{2} \mathrm{O}_{3}\right)$ in the properties the multilayer $\mathrm{CrN} / \mathrm{CrAlN} / \mathrm{Cr}_{2} \mathrm{O}_{3}$. All films were deposited by $\mathrm{DC}$ reactive magnetron sputtering and the influence of the oxygen flow rate was studied. The cross section SEM image shows that all coatings present a columnar structure. For the surface morphology, multilayer without top layer exhibits pyramid-like surface features. Whereas, films with a layer of $\mathrm{Cr}_{2} \mathrm{O}_{3}$ represent a form of a cauliflower-like structure. Also, the application of a top layer improves mechanical properties. In fact, by adding a layer of $\mathrm{Cr}_{2} \mathrm{O}_{3}$, the hardness and the adhesion increase. For tribological properties, we noted that, the application of a top layer hasn't any influence. This may be attributed to the small thickness of the layer of $\mathrm{Cr}_{2} \mathrm{O}_{3}$.

\section{References}

1. Alirezaei S, Monirvaghefi SM, Salehi M, Saatchi A (2007) Wear behavior of Ni-P and Ni-P$\mathrm{Al}_{2} \mathrm{O}_{3}$ electroless coatings. Wear 262:978-985. https://doi.org/10.1016/j.wear.2006.10.013

2. Alirezaei S, Monirvaghefi SM, Salehi M, Saatchi A (2004) Effect of alumina content on surface morphology and hardness of $\mathrm{Ni}-\mathrm{PAl}_{2} \mathrm{O}_{3}(\alpha)$ electroless composite coatings. Surf Coat Technol 184:170-175. https://doi.org/10.1016/j.surfcoat.2003.11.013

3. Barshilia HC, Surya Prakash M, Poojari A, Rajam KS (2004) Corrosion behavior of nanolayed $\mathrm{TiN}$ y $\mathrm{NbN}$ multilayer coatings prepared by reactiveer direct current magnetron sputtering process. Thin Solid Film 460:133-142. https://doi.org/10.1016/j.tsf.2004.01.096

4. Barshilia HC, Rajam KS (2008) Growth and characterization of chromium oxide coatings prepared by pulsed-direct current reactive unbalanced magnetron sputtering. Appl Surf Sci 255:2925-2931. https://doi.org/10.1016/j.apsusc.2008.08.057

5. Celik E, Tekmen C, Ozdemir I, Cetinel H, Karakas Y, Okumus SC (2003) Effects on performance of $\mathrm{Cr}_{2} \mathrm{O}_{3}$ layers produced on Mo/cast-iron materials. Surf Coat Technol 175:1074-1081. https://doi.org/10.1016/S0257-8972(03)00361-X

6. Chang C, Yen SK (2004) Characterization of electrolytic $\mathrm{ZrO}_{2} / \mathrm{Al}_{2} \mathrm{O}_{3}$ double layer coatings on AISI 440C stainless steel. Surf Coat Technol 182:242-250. https://doi.org/10.1016/ S0257-8972(03),00862-4

7. Gaillard Y, Rico VJ, Jimenez-Pique E, Gonzalez-Elipe A (2009) Nanoindentation of $\mathrm{TiO}_{2}$ thin films with different microstructures. J Phys D Appl Phys 42:145305-145314. https:// doi.org/10.1088/0022-3727/42/14/145305

8. Helmersson U, Todorova S, Barnett SA et al (1987) Growth of single-crystal TiN/VN strained-layer superlattices with extremely high mechanical hardness. J Appl Phys 481:1-5. https://doi.org/10.1063/1.339770 
9. Ho Wei-Yu, Huang D-H, Huang L-T, Hsu C-H, Wang D-Y (2004) Study of characteristics of $\mathrm{Cr}_{2} \mathrm{O}_{3} / \mathrm{CrN}$ duplex coatings for aluminum die casting applications. Surf Coat Technol 178:172-177. https://doi.org/10.1016/j.surfcoat.2003.06.017

10. Hones P, Diserens M, Lévy F (1999) Characterization of sputter-deposited chromium oxide thin films. Surf Coat Technol 121:277-283. https://doi.org/10.1016/S0257-8972(99),00384-9

11. Huang S, Chen S, Kuo Y et al (2011) Mechanical and tribological properties evaluation of cathodic arc deposited CrN/ZrN multilayer coatings. Surf Coat Technol 206:1744-1752. https://doi.org/10.1016/j.surfcoat.2011.10.029

12. Ichimura H, Rodrigob A (2000) The correlation of scratch adhesion with composite hardness for TiN coatings. Surf Coat Technol 126:152-158. https://doi.org/10.1016/S0257-8972 (00),00541-7

13. Kim H, Koh Y, Kim H (2000) Densification and mechanical properties of $\mathrm{B}_{4} \mathrm{C}$ with $\mathrm{Al}_{2} \mathrm{O}_{3}$ as a sintering aid. J Am Ceram Soc 65:2863-2865. https://doi.org/10.1111/j.1151-2916.2000. tb01647.x

14. Kong M, Wu X, Huang B, Li G (2009) Epitaxial growth and superhardness effect of TiN/AlON nanomultilayers synthesized by reactive magnetron sputtering technology. J Alloy Compd 485:435-438. https://doi.org/10.1016/j.jallcom.2009.05.133

15. Li W, Liu P, Wang J et al (2011) Microstructure and mechanical properties of $\mathrm{TiAlN} / \mathrm{SiO}_{2}$ nanomultilayers synthesized by reactive magnetron sputtering. Mater Lett 65:636-638. https://doi.org/10.1016/j.matlet.2010.11.073

16. Lin C, Tsai Y, Duh J (2010) Effect of grain size on mechanical properties in CrAlN/SiNx multilayer coatings. Thin Solid Films 518:7312-7315. https://doi.org/10.1016/j.tsf.2010.04.100

17. Liu H, Tao J, Xu J, Chen Z, Gao Q (2009) Corrosion and tribological behaviors of chromium oxide coatings prepared by the glow-discharge plasma technique. Surf Coat Technol 204:28-36. https://doi.org/10.1016/j.surfcoat.2009.06.020

18. Luo F, Gao K, Pang X, Yang H, Qiao L, Wang Y (2008) Characterization of the mechanical properties and failure modes of hard coatings deposited by RF magnetron sputtering. Surf Coat Technol 202:3354-3359. https://doi.org/10.1016/j.surfcoat.2007.12.020

19. Luo F, Pang X, Gao K, Yang H, Wang Y (2007) Role of deposition parameters on microstructure and mechanical properties of chromium oxide coatings. Surf Coat Technol 202:58-62. https://doi.org/10.1016/j.surfcoat.2007.04.066

20. Mahieu S, Depla D (2009) Reactive sputter deposition of TiN layers: modelling the growth by characterization. J Phys D Appl Phys 42:053002. https://doi.org/10.1088/0022-3727/42/ $5 / 053002$

21. Mori T, Fukuda S, Takemura Y (2001) Improvement of mechanical properties of Ti/TiN multilayer film deposited by sputtering. Surf Coat Technol 140:122-127. https://doi.org/10. 1016/S0257-8972(01),01021-0

22. Rahmoun K, Iost A, Keryvin V, Guillemot G, Chabane Sari NE (2009) A multilayer model for describing hardness variations of aged porous silicon low-dielectric-constant thin films. Thin Solid Films 518:213-221. https://doi.org/10.1016/j.tsf.2009.07.040

23. Sproul WD (1996) Reactive sputter deposition of polycrystalline nitride and oxide superlattice coatings. Surf Coat Technol 87:170-176. https://doi.org/10.1016/S0257-8972 (96), 02977-5

24. Wang Z, Zhang D, Ke P, Liu X, Wang A (2015) Influence of substrate negative bias on structure and properties of TiN coatings prepared by hybrid HIPIMS method. J Mater Sci Technol 31:37-42. https://doi.org/10.1016/j.jmst.2014.06.002

25. Yue J, Liu Y, Li G (2008) Microstructure and mechanical properties of $\mathrm{VN} / \mathrm{SiO}_{2}$ nanomultilayers synthesized by reactive sputtering. Mater Lett 62:1621-1623. https://doi. org/10.1016/j.matlet.2007.09.040 